\title{
Adolescent Morphine Exposure Affects Long-Term Microglial Function and Later-Life Relapse Liability in a Model of Addiction
}

\author{
Jaclyn M. Schwarz ${ }^{1}$ and Staci D. Bilbo ${ }^{1}$ \\ ${ }^{1}$ Department of Psychology and Neuroscience, Duke University, Durham, North Carolina 27705
}

\begin{abstract}
Adolescence in humans represents a unique developmental time point associated with increased risk-taking behavior and experimentation with drugs of abuse. We hypothesized that exposure to drugs of abuse during adolescence may increase the risk of addiction in adulthood. To test this, rats were treated with a subchronic regimen of morphine or saline in adolescence, and their preference for morphine was examined using conditioned place preference (CPP) and drug-induced reinstatement in adulthood. The initial preference for morphine did not differ between groups; however, rats treated with morphine during adolescence showed robust reinstatement of morphine CPP after drug re-exposure in adulthood. This effect was not seen in rats pretreated with a subchronic regimen of morphine as adults, suggesting that exposure to morphine specifically during adolescence increases the risk of relapse to drug-seeking behavior in adulthood. We have previously established a role for microglia, the immune cells of the brain, and immune molecules in the risk of drug-induced reinstatement of morphine CPP. Thus, we examined the role of microglia within the nucleus accumbens of these rats and determined that rats exposed to morphine during adolescence had a significant increase in Toll-like receptor 4 (TLR4) mRNA and protein expression specifically on microglia. Morphine binds to TLR4 directly, and this increase in TLR4 was associated with exaggerated morphine-induced TLR4 signaling and microglial activation in rats previously exposed to morphine during adolescence. These data suggest that long-term changes in microglial function, caused by adolescent morphine exposure, alter the risk of drug-induced reinstatement in adulthood.
\end{abstract}

\section{Introduction}

The brain continues to undergo developmental changes throughout adolescence and early adulthood (Spear, 2000). In particular, brain regions that are necessary for critical thinking and decision making remain underdeveloped in the adolescent brain relative to the adult brain (Galvan et al., 2006). As a result, adolescents are more likely to engage in risk-taking behavior and, in particular, increased experimentation with drugs of abuse (Baumrind, 1987; Wills et al., 1994, 1996). Similarly, exposure to drugs of abuse during adolescence has the potential to impact the development of the brain and affect life-long behavior. Work from our laboratory demonstrates that developmental events can have a lasting influence on microglia, the primary immune cells in the brain, including their development and function. This in turn affects behaviors that are directly impacted by microglial function, including addiction, and learning and memory (Bilbo, 2010; Bland

Received May 24, 2012; revised Nov. 20, 2012; accepted Nov. 21, 2012.

Author contributions: J.M.S. and S.D.B. designed research; J.M.S. performed research; J.M.S. analyzed data; J.M.S. and S.D.B. wrote the paper.

This work was supported by National Institutes of Health Grant R01DA025978 to S.D.B. and National Institutes of Health Grant F32DA030136 to J.M.S. We thank Ashwin Agarwal, Sonia Sabater, and Susan H. Smith for technical assistance.

The authors declare no competing financial interests.

Correspondence should be addressed to Dr. Jaclyn M. Schwarz, 572 Research Drive, Room 3017, Box 91050, Durham, NC 27705. E-mail: jaclyn.schwarz@duke.edu.

DOI:10.1523/JNEUROSCI.2516-12.2013

Copyright $\odot 2013$ the authors $\quad 0270-6474 / 13 / 330961-11 \$ 15.00 / 0$ et al., 2010a; Schwarz et al., 2011; Williamson et al., 2011). For example, we previously determined that increased maternal care attenuates morphine-induced microglial activation within the nucleus accumbens (NAcc) in adulthood, which decreases the risk of the drug-induced reinstatement of drug-seeking behavior in a model of conditioned place preference (CPP) (Schwarz et al., 2011). In the current study, we hypothesized that exposure to drugs of abuse during adolescence may alter the development and function of microglia and thus increase the risk of drugseeking behavior into adulthood. Epidemiological evidence from humans suggests that adolescents who use drugs of abuse are more likely to use drugs of abuse in adulthood, although the potential mechanism underlying this link has not been explored (Robins and Przybeck, 1985; Simoni-Wastila and Yang, 2006). The novel results presented here demonstrate that rats exposed to morphine during adolescence exhibit an increased risk of relapse to drug-seeking behavior in adulthood caused by long-term changes in microglial function within the NAcc.

\section{Materials and Methods}

General Methods

Subjects. Sprague Dawley rats (32-35 d or 49-52 d) were obtained from Harlan and housed in polypropylene cages with ad libitum access to food and water. The colony was maintained at $22^{\circ} \mathrm{C}$ on a $12: 12 \mathrm{~h}$ light-dark cycle (lights on at $0700 \mathrm{EST}$ ). All experiments were performed in males.

Drugs. Morphine sulfate and ibudilast were obtained from the National Institute on Drug Abuse Drug Inventory Supply. Minocycline hydrochloride was obtained from Sigma-Aldrich. Morphine sulfate was 
prepared and is reported as free base concentrations. Ibudilast was dissolved in a $35 \%$ polyethylene glycol/65\% saline solution, warmed to $50^{\circ} \mathrm{C}$. Minocycline hydrochloride $(25 \mathrm{mg} / \mathrm{kg}$ ) was dissolved in water for gavage $(2.5 \mathrm{ml} / \mathrm{kg})$. Ibudilast and minocycline are both effective inhibitors of glial proinflammation caused by morphine or an immune challenge (Schwarz et al., 2011; Williamson et al., 2011); Minocycline was used in Experiment 1 (see Experiment 1: adolescent subchronic morphine treatment) because ibudilast has slightly mild sedative effects that make it difficult to test preference but that do not inhibit general cognitive function or learning (Schwarz et al., 2011). Ibudilast, which inhibits both microglia and astrocytes, was used in Experiment 3 (not in the context of CPP) based on our previous data using this drug, which indicates that it can effectively block the synthesis of cytokines and chemokines within the NAcc produced by morphine treatment (Schwarz et al., 2011).

Elevated plus maze. The maze consists of two open arms and two closed arms $(50.8 \times 12.7 \mathrm{~cm})$. The closed arms have $45-\mathrm{cm}$-high black walls, and the maze is mounted $86 \mathrm{~cm}$ off the floor. Rats were placed into the central start area and allowed to explore the maze for $5 \mathrm{~min}$. The number of visits to each arm and the time spent in the open arms, closed arms, and central area were recorded.

Conditioned place preference. An unbiased CPP paradigm was used for these experiments within a two-chamber shuttle box that is divided into two equal-sized compartments. One side of the box was white with a grid floor, and the other side of the box was black with a rod floor (catalog no. MED-CPP2-RSAT, Med Associates). Activity was measured with automated data collection using photo beam strips and a computer interface with Med-PC IV software. On day 1 (d1), rats were placed into the chamber, alternating the side into which the animal was introduced, and the time spent in each side of the box was measured for $20 \mathrm{~min}$ (pretest). On $\mathrm{d} 2$ and $\mathrm{d} 3$, rats had two conditioning sessions: one in the morning between 8 A.M. and 12 noon and one in the afternoon between 1 P.M. and 5 P.M. Rats were randomly assigned to be conditioned to morphine in either the white or black box and during either the morning or afternoon, counterbalancing this parameter across treatment groups using an "unbiased assignment procedure" (Cunningham et al., 2006). During the conditioning sessions, rats were injected alternately with either morphine (see doses for individual experiments below) or saline $(1 \mathrm{ml} / \mathrm{kg}$ ) and placed into one side of the conditioning chamber with the guillotine door shut for $45 \mathrm{~min}$. The order of administration was randomized across treatment groups. On d4, testing occurred between 2 P.M. and 4 P.M. Rats were placed into the chamber, and the time spent in each side of the box was measured for $20 \mathrm{~min}$ (post-test). The CPP score was determined by subtracting the time spent in the morphine-paired box during the post-test from the time spent in the morphine-paired box during the pretest.

Extinction. Rats were placed into the CPP chamber with the guillotine door open for $5 \mathrm{~min}$ sessions, three times per week. After three $5 \mathrm{~min}$ sessions each week, the rats received an extinction test the next day, which consisted of a 20 min session with the guillotine door open. Time spent in the morphine-paired box during the pretest was subtracted from the time spent in the morphine-paired box during each extinction test.

Microglial immunohistochemistry. Postfixed brain hemispheres were sliced through the NAcc in a 1:5 series at $30 \mu \mathrm{m}(2.28-1.08 \mathrm{~mm}$ from bregma, according to Paxinos and Watson (2005).

The ionized calcium-binding adaptor molecule (Iba1) protein was used for the analysis of microglia because it is specific to microglia within the parenchyma, and its expression is constitutive (Imai et al., 1996). Sections were stained as previously reported (Bilbo and Tsang, 2010).

Quantification of Ibal densitometry was achieved from digitized images of tissue sections $(\times 10)$ using Scion Image. Sections were captured and digitized using a Nikon Eclipse 80i microscope and digital camera (Nikon). Signal pixels of a region of interest were defined as having a gray value of 3 SDs above the mean gray value of a cell-sparse area close to the region of interest. The number of pixels and the average gray values above the set background were then computed for each region of interest and multiplied, giving an integrated density measurement. One measurement was made for each of 6 different sections per animal for the NAcc (including core and shell). All 6 values for each NAcc were averaged to obtain a single integrated density value for each rat.

Quantitative real-time PCR. RNA was isolated from NAcc microdissections using the TRIzol method and was subsequently DNase-treated. To measure Toll-like receptor 4 (TLR4), CD11b, and GFAP mRNA, cDNA was synthesized from 150 ng of isolated RNA using the QuantiTect Reverse Transcription Kit from QIAGEN, and gene expression was measured using quantitative real-time PCR and the in-house designed primers listed below using the QuantiTect SYBR Green PCR Kit from QIAGEN following the manufacturer's protocol. For the analysis of all other genes, cDNA was synthesized from $500 \mathrm{ng}$ of isolated RNA using the $\mathrm{RT}^{2}$ First Strand Kit (catalog no. C-03; SA Biosciences QIAGEN), and gene expression was measured using quantitative real-time PCR with stock primers designed to measure 84 genes central to TLR-mediated signal transduction pathways (SA Biosciences QIAGEN; catalog no. PARN-018) following the manufacturer's protocol.

Primer specifications. GAPDH: forward, GTTTGTGATGGGTGTGAACC; reverse, TCTTCTGAGTGGCAGTGATG; TLR4: forward, CAGAGGAAGAACAAGAAGC; reverse, CCAGATGAACTGTAGCATTC; CD11b: forward, CTGGGAGATGTGAATGGAG; reverse, ACTGATGCTGGCTACTGATG; GFAP: forward, AGGGACAATCTCACACAGG; reverse, GACTCAACCTTCCTCTCCA.

Quantitative RT-PCR analysis. Threshold amplification cycle number $\left(C_{t}\right)$ was determined for each reaction within the linear phase of the amplification plot, and relative gene expression was determined from GAPDH using the $2^{-\Delta \Delta C T}$ method.

Microglial isolation. Isolated NAcc and hippocampi (HP) were diced into small pieces using a sterile razor, transferred into a $2 \mathrm{ml}$ sterile tube with $1 \mathrm{ml}$ of HBSS (without calcium and magnesium) (Invitrogen), and spun at $300 \times g$ at room temperature for $2 \mathrm{~min}$. Tissue was then brought to a single-cell suspension using the Miltenyi Neural Tissue Dissociation Kit (P) (Miltenyi Biotec) according to the manufacturer's instructions. After a final wash in $\mathrm{HBSS}$ containing $\mathrm{CaCl}_{2}$ and $\mathrm{MgCl}_{2}$, tissue was incubated with anti-myelin microbeads (Miltenyi Biotec) in MACS buffer (PBS containing 0.5\% BSA and $2 \mathrm{~mm}$ EDTA, $\mathrm{pH} 7.2$ ) for $15 \mathrm{~min}$ at $4^{\circ} \mathrm{C}$. Tissue was then washed with $5 \mathrm{ml}$ of MACS buffer and centrifuged at $300 \times g$ at $4^{\circ} \mathrm{C}$ for $10 \mathrm{~min}$. The tissue was resuspended in $500 \mu \mathrm{l}$ MACS buffer and passed through a $70 \mu \mathrm{m}$ nylon filter onto LD columns (Miltenyi Biotec) exposed to a strong magnetic field. The flow through (demyelinated cells) and subsequent washes were collected into a $5 \mathrm{ml}$ polypropylene tube and centrifuged at $300 \times g$ at $4^{\circ} \mathrm{C}$ for $10 \mathrm{~min}$. The demyelinated cells were immediately stained for flow cytometric analysis as follows.

Fluorescence staining and flow cytometry. Demyelinated cells were washed once in $2 \mathrm{ml}$ PBS supplemented with $0.5 \%$ BSA and 2 mM EDTA (wash buffer), followed by centrifugation at $350 \times g$ for $5 \mathrm{~min}$. The wash buffer was removed by aspiration and the pellet dispersed by vortexing. Cells were incubated with $5 \mu \mathrm{l}$ rat Fc receptor block (CD32; BD Biosciences PharMingen) for $5 \mathrm{~min}$ at $4^{\circ} \mathrm{C}$. Next, cells were incubated for 20 min at $4^{\circ} \mathrm{C}$ in the dark with $100 \mu \mathrm{l}$ of antibody mixture, including allophycocyanin-conjugated mouse anti-rat CD11b/c (BD Biosciences PharMingen), diluted 1:1000, and rabbit anti-TLR4 (Cell Signaling Technology), diluted 1:100. Cells were washed in buffer before being incubated in $100 \mu \mathrm{l}$ secondary antibody, phycoerythrin-conjugated donkey anti-rabbit IgG (eBioscience), diluted 1:500, for $15 \mathrm{~min}$ at $4^{\circ} \mathrm{C}$ in the dark. The cells were washed and spun down at $350 \times g$ for 5 min and fixed in $200 \mu \mathrm{l} 1.5 \%$ paraformaldehyde before analysis using a FACSCanto II flow cytometer (BD Biosciences) and FlowJo software (TreeStar). For each sample, 10,000 events were collected and doublets excluded from the analysis based on properties of size (forward scatter height and area, see Fig. 8).

Statistical analysis. A two-tailed Student's $t$ test (morphine vs saline, $\alpha$ level $=0.05$ ) or a one-way ANOVA (morphine and ibudilast treatments) was used to analyze CPP data, as well as subsequent reinstatement data. Significant overall effects using one-way ANOVA were followed up with the Tukey's post hoc test (with $p<0.05$ ) to determine group differences. Ibal densitometry was compared using a two-tailed Student's $t$ test (morphine vs saline, $\alpha$ level $=0.05$ ). Relative gene expression across groups was compared using either a two-tailed Student's $t$ test (morphine 


\section{A Experiment 1: Adolescent Sub-Chronic Morphine Treatment}

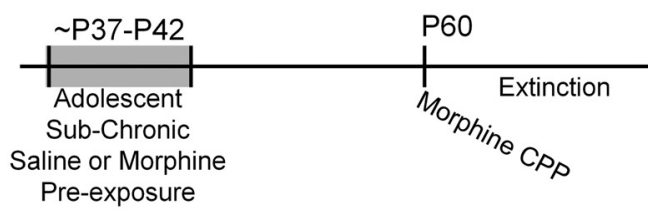

B Experiment 2: Adult Sub-Chronic Morphine Treatment

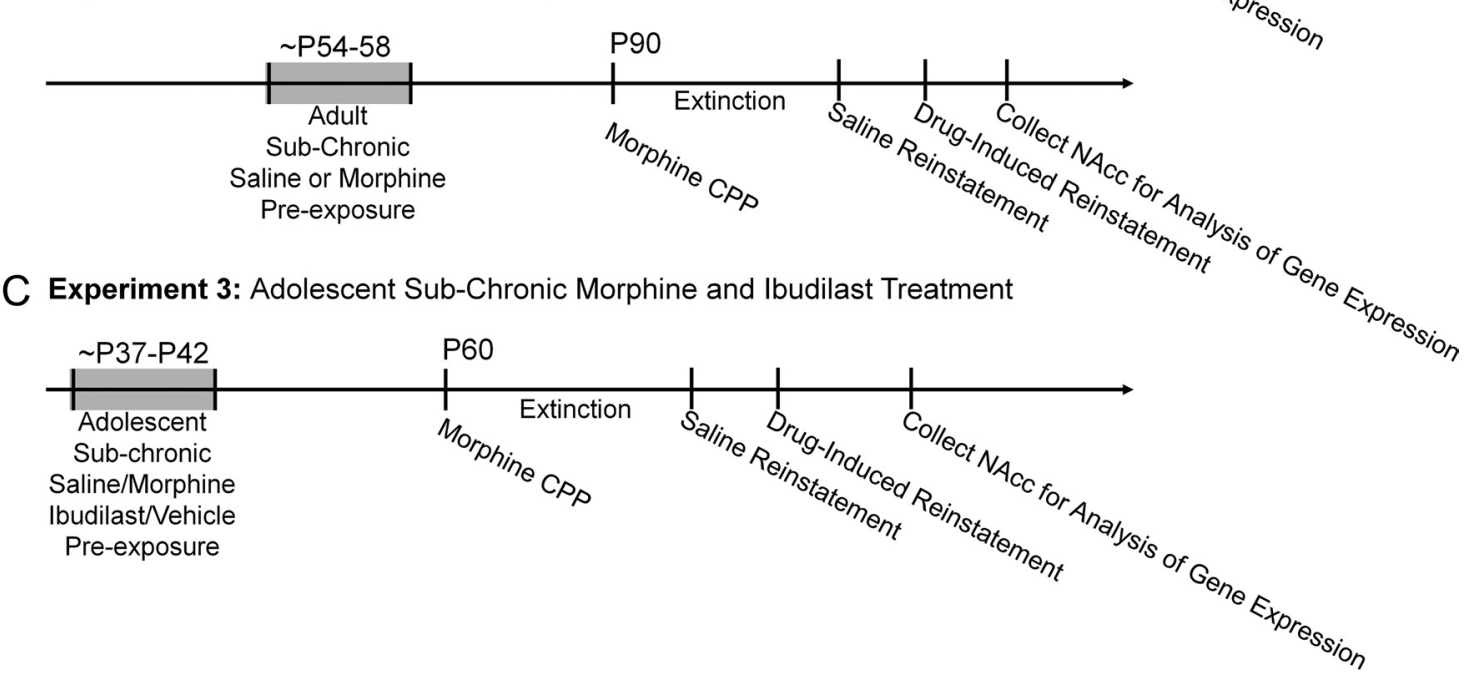

Figure 1. Timeline of Experiments 1, 2, and 3. A, Rats were treated in adolescence [beginning approximately postnatal day (P) 37-42] with a subchronic regimen of either saline or morphine. On P60, rats began CPP for morphine followed by extinction, saline-induced reinstatement, and subsequently drug-induced reinstatement of morphine CPP. Within $48 \mathrm{~h}$ after the completion of behavior, the NAcc was collected for the analysis of CD11b and TLR4 gene expression. B, Rats were treated in adulthood (beginning approximately P54-P58) with a subchronic regimen of either saline or morphine. On P90, rats began (PP for morphine followed by extinction, saline-induced reinstatement, and subsequently drug-induced reinstatement of morphine CPP. Within $48 \mathrm{~h}$ after the completion of behavior, the NAcc was collected for the analysis of CD11b and TLR4 gene expression. C, Rats were treated during adolescence (beginning approximately P37-P42) with a subchronic regimen of either saline or morphine and the glial modulator, ibudilast, or its vehicle. On P60, rats began CPP for morphine followed by extinction, saline-induced reinstatement, and subsequently drug-induced reinstatement of morphine CPP. Within $48 \mathrm{~h}$ after the completion of behavior, the NAcc was collected for the analysis of TLR4 gene expression.

vs saline, $\alpha$ level $=0.05$ ) or a two-way ANOVA with adolescent treatment (saline or morphine) and adult treatment (saline and morphine) as factors $(\alpha$ level $=0.01)$. A one-tailed $t$ test was used to analyze the fluorescent staining intensity of TLR4 protein and CD11b protein after flow cytometry $(\alpha$ level $=0.05)$. A two-way within-subjects ANOVA was used to analyze data from the Elevated Plus Maze. Significant interactions using a two-way ANOVA were followed up with the Holm-Sidak post hoc test (with $p<0.05$ ) to determine potential group differences. All data in graphical form represent the mean \pm SEM.

\section{Experiment 1: adolescent subchronic morphine treatment}

The goal of this experiment was to determine whether exposure to morphine during adolescence alters morphine CPP, extinction, or druginduced reinstatement of morphine CPP in adulthood, and if so, whether markers of microglial function/innate immune signaling are significantly altered within the NAcc of these rats.

Treatment and CPP. Adolescent rats $(\sim 37-40 \mathrm{~d})$ were randomly assigned to the following pre-exposure treatment groups: either subchronic morphine or saline twice a day (8 A.M. and 4 P.M.) for $5 \mathrm{~d}$ (Fig. $1 A$ ). On $\mathrm{d} 1$ and $\mathrm{d} 2$, the dose of morphine was $4 \mathrm{mg} / \mathrm{kg}$ intraperitoneally (i.p.); and on d3, d4, and d5, each dose of morphine was $8 \mathrm{mg} / \mathrm{kg}$ i.p. Rats were housed in pairs of the same treatment group until behavioral testing began in adulthood (60-63 d). CPP and extinction were performed as described above (see Conditioned place preference), except that the conditioning dose of morphine in this experiment was $4 \mathrm{mg} / \mathrm{kg}$ (i.p.). One rat showed a strong preference for one side of the box on d1 [the rat spent more than two-thirds of the total time ( $800 \mathrm{~s}$ ) in one side of the box] and was eliminated from the experiments and replaced with another rat. Within $48 \mathrm{~h}$ after the completion of all behavioral tasks (Fig. $1 A$ ), the rats were killed, and half of the brain was collected for mRNA analysis of
CD11b and TLR4 and the other half of the brain was submersion fixed in $4 \%$ paraformaldehyde for $4 \mathrm{~d}$ for immunohistochemical detection of Ibal.

Intraperitoneal versus subcutaneous treatment. In Experiment 1, all morphine and saline treatments were administered i.p. In subsequent experiments, all morphine and saline treatments were administered subcutaneously (s.c.) for greater consistency with the literature. When we changed the route of administration from i.p. to s.c., we performed a set of experiments which allowed us to determine that morphine CPP produced by $8 \mathrm{mg} / \mathrm{kg}$ i.p. $(149.2 \pm 38.2)$ was nearly identical to that produced by $4 \mathrm{mg} / \mathrm{kg}$ s.c. $(144.7 \pm 38.6)$. In addition, the two doses (via different routes of administration) produce an identical effectiveness and time course of effectiveness on the hot plate (data not shown), which suggests that the pharmacokinetics of the two doses is identical. Thus, in the CPP experiments described in Experiments 2 and 3, even though we decreased the morphine dose from $8 \mathrm{mg} / \mathrm{kg}$ (i.p.) to $4 \mathrm{mg} / \mathrm{kg}$ (s.c.), we obtained similar, if not better, CPP. Importantly, our findings (both behavioral and molecular) remained consistent regardless of the route and/or dose of morphine administration.

\section{Experiment 2: adult subchronic morphine treatment}

Having determined that exposure to morphine during adolescence increases reinstatement to CPP after re-exposure to morphine in adulthood, the goal of this experiment was to determine whether pre-exposure to morphine in adulthood would similarly increase the likelihood of drug-induced reinstatement to morphine CPP assessed several weeks later.

Treatment and CPP. Adult rats $(\sim 54-57 \mathrm{~d})$ were randomly assigned to the following pre-exposure treatment groups: either morphine or saline twice a day (8 A.M. and 4 P.M.) for $5 \mathrm{~d}$ (Fig. $1 B$ ). On $\mathrm{d} 1$ and $\mathrm{d} 2$, the dose 
of morphine was $4 \mathrm{mg} / \mathrm{kg}$ s.c.; and on $\mathrm{d} 3, \mathrm{~d} 4$, and $\mathrm{d} 5$, each dose of morphine was $8 \mathrm{mg} / \mathrm{kg}$ s.c. Rats were housed in pairs of the same treatment group until behavioral testing began. CPP began $30 \mathrm{~d}$ after the subchronic treatment began (84-87 d). CPP and extinction were performed as described above (see Conditioned place preference), except that the conditioning dose of morphine in this experiment was $4 \mathrm{mg} / \mathrm{kg}$ s.c. Within $48 \mathrm{~h}$ after the completion of all behavioral tasks, the rats were killed, and half of the brain was collected for mRNA analysis of CD11b and TLR4 (Fig. 1B).

\section{Experiment 3: adolescent subchronic morphine and ibudilast treatment}

The goal of this experiment was to determine whether exposure to morphine during adolescence increases the likelihood of reinstatement to morphine CPP via an impact on glia.

Treatment and CPP. Adolescent rats ( 37-40 d) were randomly assigned to the following pre-exposure treatment groups: saline + vehicle, saline + ibudilast, morphine + vehicle, or morphine + ibudilast. On $\mathrm{d} 1$ and $\mathrm{d} 2$, the dose of morphine was $4 \mathrm{mg} / \mathrm{kg}$ s.c.; and on $\mathrm{d} 3, \mathrm{~d} 4$, and $\mathrm{d} 5$, each dose of morphine was 8 $\mathrm{mg} / \mathrm{kg}$ s.c. Rats were treated with the aforementioned doses of morphine or saline twice a day (8 A.M. and 4 P.M.) for 5 d (Fig. 1C). Thirty minutes before the first treatment each day, rats received a single dose of either ibudilast $(7.5 \mathrm{mg} / \mathrm{kg}$, i.p.) or vehicle ( $1 \mathrm{ml} / \mathrm{kg}$, i.p.). Rats were housed in pairs of the same treatment group until behavioral testing began in adulthood $(60 \mathrm{~d})$. CPP began $30 \mathrm{~d}$ after the first treatment $(60-63 \mathrm{~d})$. CPP and CPP extinction were performed as described above (see Conditioned place preference), except that the conditioning dose of morphine in this experiment was $4 \mathrm{mg} / \mathrm{kg}$ s.c. Within $48 \mathrm{~h}$ after the completion of all behavioral tasks, the rats were killed, and the brain was collected for mRNA analysis of CD11b and TLR4 (Fig. 1C). A second group of adolescent rats were treated with morphine or saline as described in Experiment 1 and treated again in adulthood (P60) with a single dose of morphine ( $4 \mathrm{mg} / \mathrm{kg}$, s.c.) or saline $20 \mathrm{~min}$ before being killed to assess the acute TLR signaling and microglial response to morphine within the NAc.

\section{Results}

\section{Experiment 1: adolescent subchronic morphine treatment}

The goal of this experiment was to determine whether preexposure to morphine during adolescence would increase CPP to morphine in adulthood and/or increase the risk of drug-induced reinstatement of morphine CPP after extinction. All rats, regardless of adolescent pre-exposure with saline or morphine, showed a preference for morphine during CPP in adulthood (Fig. $2 \mathrm{~A}$, $\left.t_{(22)}=-0.18 ; p=0.85\right)$. After 4 weeks of extinction, re-exposure to morphine $(8 \mathrm{mg} / \mathrm{kg}$ i.p.) elicited strong reinstatement of CPP only in rats that had been treated with morphine during adolescence (Fig. $\left.2 B, t_{(22)}=-1.91 ; p=0.03\right)$. Injection with saline $(1$ $\mathrm{ml} / \mathrm{kg}$, i.p.) did not cause the reinstatement of morphine CPP (Fig. 2B).

To test whether attenuating microglial activation at the time of morphine re-exposure could prevent drug-induced reinstatement, rats were administered minocycline $(25 \mathrm{mg} / \mathrm{kg})$ at $24 \mathrm{~h}$ and $30 \mathrm{~min}$ before morphine re-exposure. Minocycline did not block the reinstatement of morphine CPP in rats previously treated with morphine during adolescence (Fig. $2 C, t_{(15)}=-1.84 ; p=0.04$ ).
Treatment of adolescent rats with a subchronic regimen of morphine caused a significant attenuation in weight gain, which resulted in a significant difference in average weight between saline- and morphine-treated groups on $\mathrm{d} 4$ and $\mathrm{d} 5$ of treatment (Table 1, d4: $t_{(22)}=-2.22 ; p=0.03$; and $\mathrm{d} 5: t_{(22)}=-3.39 ; p=$ $0.002)$. In adulthood, at the time of CPP, there was no longer a significant difference in weight between the treatment groups (Table $1, t_{(22)}=0.34 ; p=0.73$ ). Given that anxiety and stress responsivity can influence addictive behaviors, we tested whether treatment of adolescent rats would affect general levels of anxiety in adulthood. We found no significant effect of adolescent treatment on anxiety as determined by the elevated plus maze (treatment $\times$ maze arm: $F_{(1,31)}=0.25 ; p=0.62$; data not shown).

\section{Experiment 2: adult subchronic morphine treatment}

Having determined that adolescent morphine exposure increases the risk of drug-induced reinstatement of morphine CPP in adulthood, the goal of this experiment was to determine whether pre-exposure to morphine in adulthood would have a similar effect on the drug-induced reinstatement of morphine CPP tested months later. All rats, regardless of adult saline and morphine pre-exposure, exhibited a preference for the morphinepaired chamber when tested $30 \mathrm{~d}$ after pre-exposure (Fig. $3 \mathrm{~A}$, $\left.t_{(22)}=-1.38 ; p=0.18\right)$. After 5 weeks of extinction, treatment with saline did not cause the reinstatement of morphine CPP (Fig. 3A). Reexposure to a priming dose of morphine did not consistently elicit reinstatement of CPP from either group of rats (Fig. 3B). A closer analysis of the data revealed that approximately half of the rats show reinstatement of morphine CPP after drug re-exposure, regardless of the adult pre-exposure condition, whereas the other half did not. This is in contrast to the previous experiment wherein rats previously exposed to morphine during adolescence consistently showed drug-induced reinstatement of 
Table 1. Weights during subchronic treatment paradigms

\begin{tabular}{|c|c|c|c|c|c|c|}
\hline & Day 1 & Day 2 & Day 3 & Day 4 & Day 5 & CPP \\
\hline \multicolumn{7}{|l|}{ Experiment 1} \\
\hline Adolescent saline & $161.5 \pm 2.2$ & $161.1 \pm 2.3$ & $177.0 \pm 2.2$ & $183.6 \pm 2.5$ & $191.6 \pm 2.4$ & $331.0 \pm 5$ \\
\hline Adolescent morphine & $164.7 \pm 1.9$ & $166.8 \pm 2.2$ & $171.6 \pm 2.3$ & $175.9 \pm 2.3^{*}$ & $179.6 \pm 2.4^{*}$ & $328.5 \pm 5$ \\
\hline \multicolumn{7}{|l|}{ Experiment 2} \\
\hline Adult saline & $247.6 \pm 2.1$ & $253.8 \pm 1.1$ & $260.2 \pm 1.6$ & $266.0 \pm 1.7$ & $271.3 \pm 1.7$ & $368.7 \pm 4.3$ \\
\hline Adult morphine & $252.1 \pm 2.2$ & $258.7 \pm 2.5$ & $264.3 \pm 2.8$ & $264.6 \pm 2.8$ & $265.0 \pm 2.9^{*}$ & $369.1 \pm 6.4$ \\
\hline \multicolumn{7}{|l|}{ Experiment 3} \\
\hline Adolescent saline + vehicle & $161.8 \pm 2.5$ & $167.6 \pm 2.6$ & $176.3 \pm 2.6$ & $183.1 \pm 3.1$ & $190.4 \pm 3.2$ & $432.1 \pm 10$ \\
\hline Adolescent morphine + vehicle & $158.8 \pm 1.4$ & $160.0 \pm 1.4$ & $163.3 \pm 1.3^{*}$ & $166.3 \pm 1.6^{*}$ & $169.5 \pm 1.7^{*}$ & $433.3 \pm 10$ \\
\hline Adolescent saline + ibudilast & $162.6 \pm 1.8$ & $168.8 \pm 1.9$ & $175.2 \pm 1.9$ & $180.9 \pm 2.0$ & $188.0 \pm 2.0$ & $408.1 \pm 34$ \\
\hline Adolescent morphine + ibudilast & $164.0 \pm 1.4$ & $164.5 \pm 1.5$ & $166.5 \pm 1.9^{*}$ & $168.5 \pm 1.6^{*}$ & $170.7 \pm 1.7^{*}$ & $425.6 \pm 9$ \\
\hline
\end{tabular}

Weights (in grams) were taken from each rat every day of the subchronic regimen, before morphine or saline administration, during Experiments 1, 2, and 3. In Experiment 1, subchronic morphine administration in adolescence resulted in a significant attenuation in weight gain, such that on days 4 and 5 of treatment, morphine-treated rats weighed significantly less than saline-treated controls ( ${ }^{*} p<0.05$ vs saline-treated controls). In Experiment 2 , subchronic morphine administration in adulthood resulted in a significant attenuation in weight gain, such that on day 5 of treatment, morphine-treated rats weighed significantly less than saline-treated controls ( ${ }^{*} p<0.05$ vs saline-treated controls). In Experiment 3, subchronic morphine administration in adolescence resulted in a significant attenuation in weight gain, such that on days 3,4 , and 5 of treatment, morphine-treated rats weighed significantly less than saline-treated controls $\left({ }^{*} p<0.05\right.$ vs saline-treated controls). This effect was not prevented by daily pretreatment with the glial modulator, ibudilast.

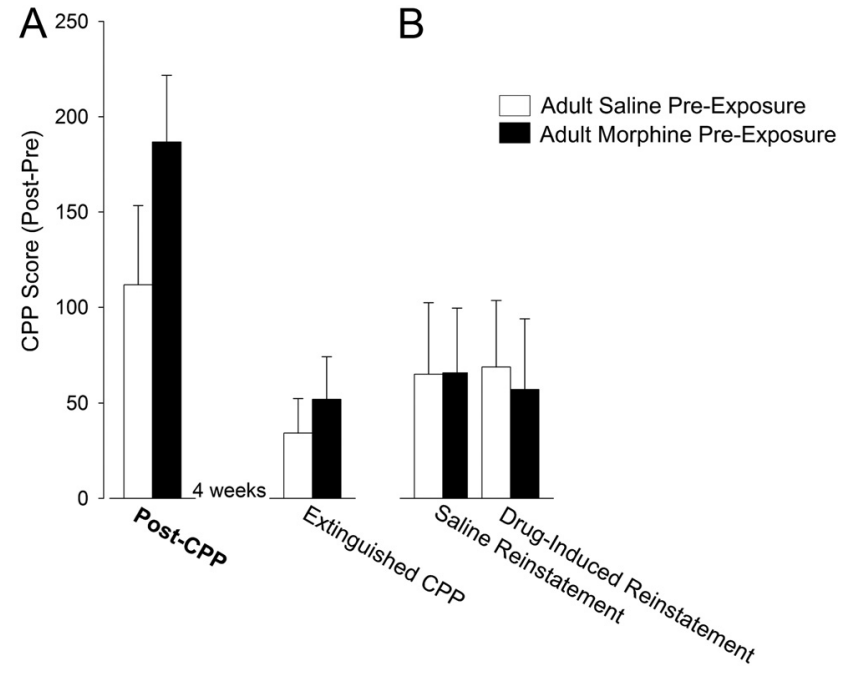

Figure 3. Adult morphine pre-exposure does not increase the long-term risk of druginduced reinstatement of morphine CPP. Adult rats, postnatal day 60 , were treated with a subchronic regimen of morphine or saline ( $n=12$ /group). $A$, Thirty days later, rats from both treatment groups showed similar levels of morphine CPP; and 4 weeks later, rats showed no preference for the morphine-paired chamber (Extinguished (PP). B, Injection of the same rats with saline (Saline Reinstatement) did not cause the reinstatement of morphine CPP. Reexposure to morphine (Drug-Induced Reinstatement) also did not lead to reinstatement of morphine CPP.

morphine CPP. The data from these experiments are represented together in a box plot (Fig. 4).

Treatment of adults with a subchronic regimen of morphine also caused an attenuation in weight gain, resulting in a significant difference in weight between saline and morphinetreated groups on $\mathrm{d} 5$ of treatment (Table $1, t_{(22)}=1.82 ; p=$ 0.04). At the time of CPP, $30 \mathrm{~d}$ later, there was no longer a significant difference in weight between the treatment groups (Table $1, t_{(22)}=-0.05 ; p=0.96$ ). Treatment of adult rats with morphine increased general levels of anxiety $30 \mathrm{~d}$ later, as determined by the elevated plus maze (treatment $\times$ maze arm: $\left.F_{(1,47)}=8.52 ; p=0.008\right)$. Rats treated previously treated with morphine spent significantly more time in the closed arms of the maze $(p=0.004)$ and less time in the open arms of the maze ( $p=0.02)$ than their controls (data not shown); however, this significant difference in anxiety did not appear to affect or correlate with the CPP scores $\left(R^{2}=0.0034 ; p=0.78\right)$ or drug-induced reinstatement scores $\left(R^{2}=0.469 ; p=0.29\right)$ in the same rats.

\section{Reinstatement Scores}

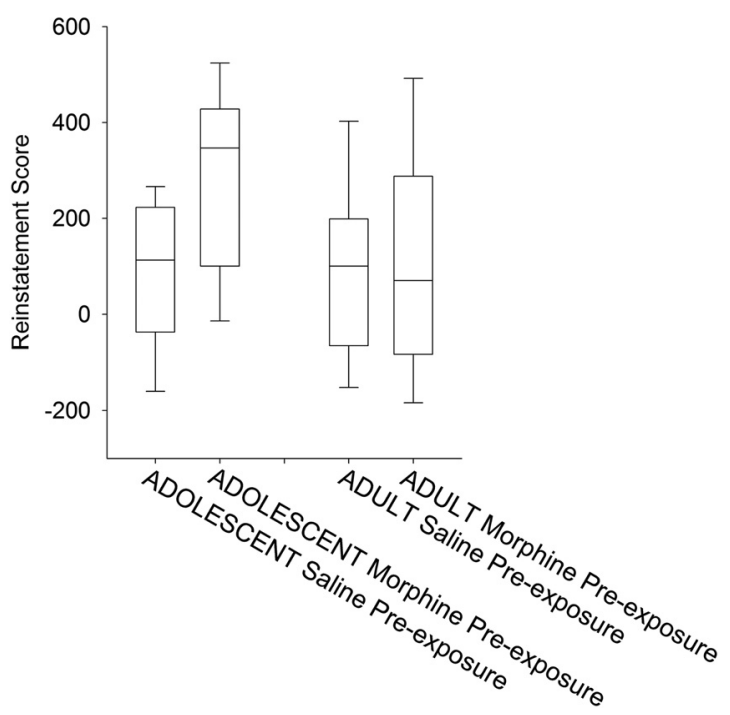

Figure 4. Box plot representation of drug-induced reinstatement scores from rats preexposed to morphine or saline in either adolescence or adulthood. Drug-induced reinstatement scores from the rats in Experiment 1 and the rats in Experiment 2 were plotted together to show the median reinstatement scores as well as the upper and lower quartiles for these reinstatement scores. Overall, rats treated with morphine during adolescence showed a significant increase in the reinstatement of morphine CPP compared with their saline controls: $p<0.05$. In contrast, the reinstatement scores from rats pre-exposed to morphine or saline in adulthood show greater variability, with approximately half of the rats in each group showing reinstatement (CPP score $>100$ ) and half of the rats not showing reinstatement to morphine CPP, resulting in no significant difference between the treatment groups.

\section{Experiment 3: adolescent subchronic morphine and ibudilast treatment}

The goal of this experiment was to determine whether the increased risk of drug-induced reinstatement of morphine CPP that was caused by adolescent pre-exposure to morphine could be attributed to the activation of glia (both microglia and astrocytes) at the time of adolescence, and thus be prevented by attenuation of glial activation in adolescence. All treatment groups, regardless of adolescent pre-exposure, exhibited similar levels of CPP to morphine (Fig. $5 A, F_{(3,47)}=0.90 ; p=0.44$ ). After 5 weeks of extinction, injection with saline did not result in the reinstatement of morphine CPP in any treatment group (Fig. 5B); however, as in Experiment 1, re-exposure to morphine ( $2 \mathrm{mg} / \mathrm{kg}$, s.c.) resulted in the reinstatement of morphine CPP only in rats that 


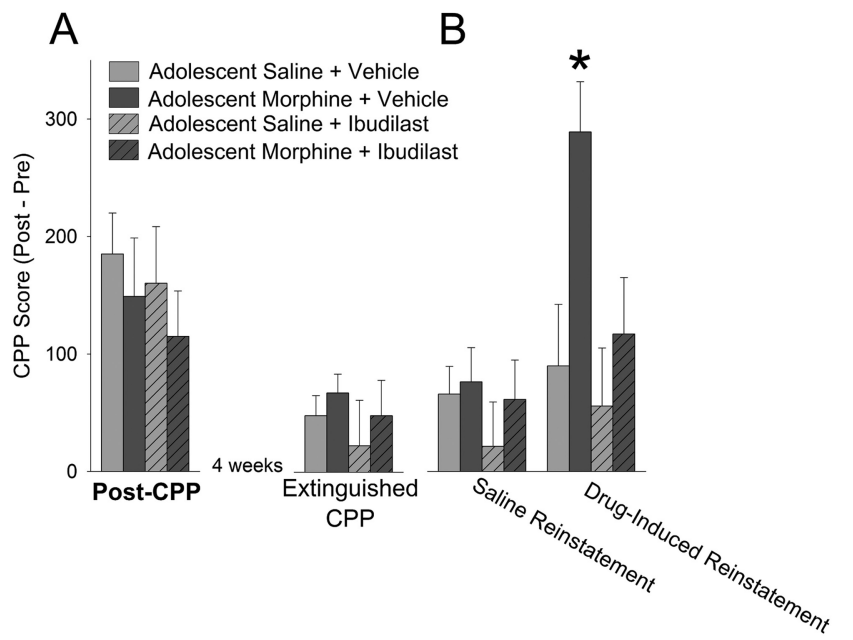

Figure 5. Attenuating glial activation with ibudilast during adolescence prevents the increased risk of drug-induced reinstatement in adulthood and the long-term increase in TLR4 expression within the NAcc. Adolescent rats were treated subchronically with either ibudilast ( $7.5 \mathrm{mg} / \mathrm{kg}$ ) or its vehicle along with morphine or saline ( $n=12 /$ group). $\boldsymbol{A}$, In adulthood, rats from all treatment groups showed similar levels of morphine (PP; and 4 weeks later, rats showed no preference for the morphine-paired chamber (Extinguished (PP). $\boldsymbol{B}$, Injection of the same rats with saline (Saline Reinstatement) did not cause the reinstatement of morphine CPP. Re-exposure to morphine (Drug-Induced Reinstatement) resulted in the selective reinstatement of morphine CPP in rats treated with morphine as adolescents: ${ }^{*} p<0.05$, compared with all other groups. This effect was prevented by treatment with ibudilast at the time of adolescent morphine exposure.

were treated with morphine as adolescents (Fig. $5 B$, overall effect: $F_{(3,46)}=5.38 ; p=0.003$; one morphine-treated rat was removed from the analysis as an outlier). Treatment of rats with ibudilast, which inhibits morphine-induced cytokine and chemokine production (Schwarz et al., 2011), in combination with morphine during adolescence prevented the reinstatement of morphine CPP months later $(p<0.01$, compared with rats treated with morphine alone during adolescence).

Analysis revealed a significant main effect of subchronic morphine treatment on average weight by $\mathrm{d} 3, \mathrm{~d} 4$, and $\mathrm{d} 5$ of the subchronic adolescent treatment (Table 1, d3: $F_{(3,47)}=9.97 ; p<$ $0.001 ; \mathrm{d} 4: F_{(3,47)}=14.99 ; p<0.001 ; \mathrm{d} 5: F_{(3,47)}=23.44 ; p<$ $0.001)$. Morphine caused a significant attenuation of weight gain, such that these morphine-treated rats weighed significantly less compared with saline-treated rats $(p<0.05)$. Pretreatment with ibudilast each did not prevent the attenuation in weight gain caused by morphine. At the time of CPP, there was no longer a significant difference in weight between the treatment groups (Table $1, F_{(3,47)}=1.05 ; p=0.37$ ). Treatment of adolescent rats with morphine and/or ibudilast did not affect general levels of anxiety in adulthood as determined by the elevated plus maze (morphine treatment $\times$ ibudilast treatment $\times$ maze arm: $F_{(1,79)}=0.006 ; p=0.93$; data not shown).

\section{Adolescent morphine pre-exposure, but not adult morphine pre-exposure, increases TLR4 mRNA expression long-term within the NAcc}

In addition to its classic opioid receptor mechanism, morphine also activates the innate immune receptor TLR4 via its adaptor molecule Lymphocyte antigen 96, also known as MD2. This activation induces the synthesis of proinflammatory cytokines and chemokines (Hutchinson et al., 2010, 2012; Schwarz et al., 2011; Wang et al., 2012). We have previously determined that morphine-induced cytokine and chemokine production specifi- cally within the NAcc is required for the drug-induced reinstatement of morphine CPP behavior and that this activation of microglia can be modulated by early life experience (Schwarz et al., 2011). Given these data, we hypothesized that adolescent morphine pre-exposure increases the risk of drug-induced reinstatement behavior in adulthood via long-term changes in TLR4/ MD2 signaling and thus morphine-induced microglial activation at the time of CPP.

To test this, we analyzed the expression of TLR 4 mRNA in the NAcc of rats pre-exposed to either morphine or saline in adolescence from Experiment 1. The tissue was collected within $48 \mathrm{~h}$ after the completion of all behavioral tasks. Analysis of these data revealed a significant increase in TLR4 mRNA expression in rats that had been treated as adolescents with morphine (Fig. $6 \mathrm{~A}$, $\left.t_{(15)}=2.23 ; p=0.04\right)$. Analysis of CD11b, an integrin molecule found on microglia that regulates cell shape, mobility and inflammation, revealed no significant effect of previous adolescent morphine treatment (Fig. $6 A, t_{(15)}=-0.953 ; p=0.33$ ). No significant difference was observed between groups in the densitometry of Iba1, a protein ubiquitously expressed on microglia, within the $\operatorname{NAcc}\left(t_{(15)}=0.15 ; p=0.61\right.$, data not shown $)$. Together, these data indicate that adolescent exposure to morphine can increase the baseline constitutive expression of TLR4 mRNA within the NAcc, without producing a long-term baseline change in CD11b or Ibal expression, which suggests that, rather than increased general activation or a change in the number of microglia within the NAcc, adolescent morphine pre-exposure produces a specific, long-term change in TLR4 expression on microglia within the NAcc.

Analysis of TLR4 and CD11b expression in the NAcc of the rats pre-exposed to either morphine or saline in adulthood from Experiment 2 and collected within $48 \mathrm{~h}$ after the completion of all behavioral testing revealed no significant effect of subchronic morphine treatment in adulthood (CD11b: $t_{(10)}=-1.27 ; p=$ 0.23 , and TLR4: $t_{(10)}=0.5 ; p=0.62$; Fig. $\left.6 B\right)$. We conclude that subchronic morphine pre-exposure in adulthood does not affect the constitutive expression of TLR4 or CD11b mRNA within the NAcc.

Finally, we analyzed the expression of TLR 4 within the NAcc of the rats pre-exposed to either morphine or saline and ibudilast or its control from Experiment 3 and collected within $48 \mathrm{~h}$ after the completion of all behavioral testing. This analysis revealed a significant overall effect of adolescent treatment (Fig. $7, F_{(3,46)}=$ 2.96; $p=0.04)$. Specifically, morphine treatment increased TLR4 expression within the NAcc compared with all other treatment groups as previously seen $(p<0.05)$. This effect was blocked by pretreatment with ibudilast during adolescence. From these data, we conclude that attenuating the activation of glia, both microglia and astrocytes, at the time of adolescent morphine exposure can prevent the long-term increase in the risk of reinstatement to drug-seeking behavior after drug re-exposure months later.

\section{Adolescent morphine exposure increases TLR4 protein} specifically on microglia from the NAcc into adulthood Given our consistent finding that morphine exposure during adolescence increases TLR4 mRNA in the NAcc, we sought to determine whether this increase in TLR4 represents an increase in TLR4 protein and the neural cell type in which this change in TLR4 expression occurs. Neural cells were collected in adulthood from the NAcc and the HP (for comparison) of rats treated with a subchronic regimen of either saline or morphine during adolescence as described in Experiment 1, and stained for CD11b and TLR4 protein for analysis using flow cytometry. Cells were ini- 


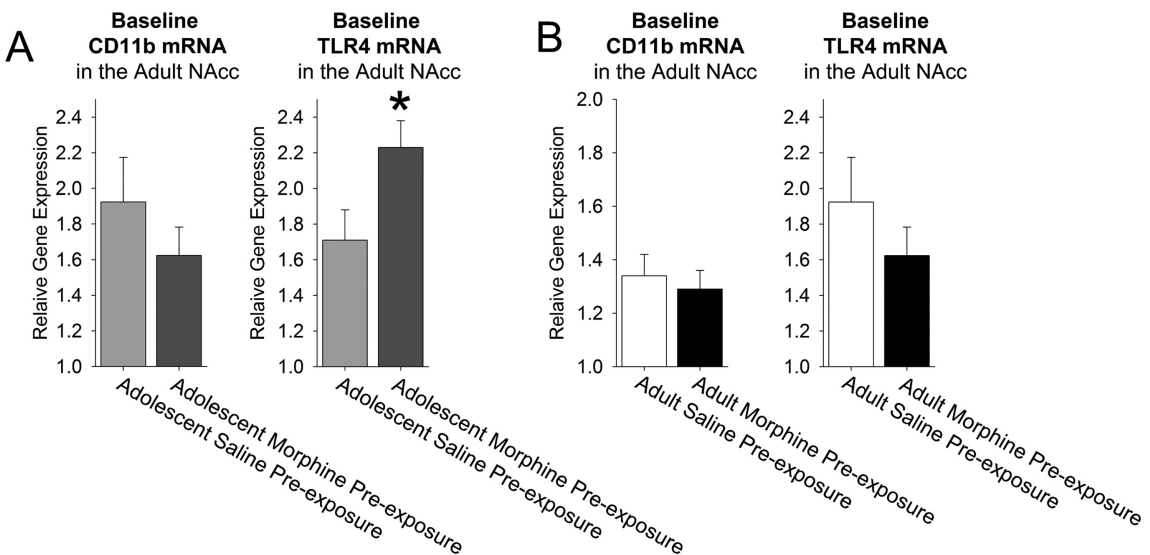

Figure 6. Adolescent morphine pre-exposure, but not adult morphine pre-exposure, results in increased TLR4 mRNA expression within the NAcc in adulthood. $\boldsymbol{A}$, In the same rats from Experiment 1 that were pre-exposed to morphine or saline in adolescence, we analyzed the baseline mRNA expression of CD11b and TLR4 within the NAcc $48 \mathrm{~h}$ after the completion of all behavioral tasks. Analysis revealed no significant effect of adolescent morphine pre-exposure on CD11b but a significant increase in TLR4 mRNA in rats pre-exposed to morphine during adolescence compared with their saline-treated controls: ${ }^{*} p<0.05$. $\boldsymbol{B}$, In the same rats from Experiment 2 that were pre-exposed to morphine or saline in adulthood, we analyzed the mRNA expression of CD11b and TLR4 within the NAcc $48 \mathrm{~h}$ after the completion of all behavioral tasks and found no significant differences in either gene.

\section{Baseline \\ TLR4 mRNA}

in the Adult NAcc

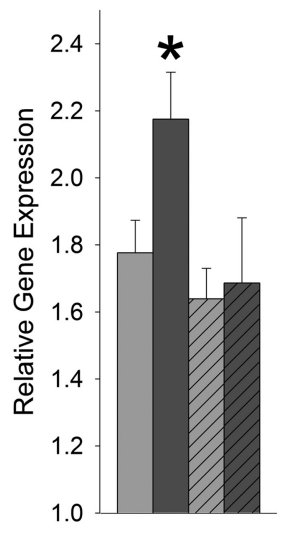

Figure 7. Attenuating glial activation with ibudilast during adolescence prevents the longterm increase in TLR4 expression within the NAcc. In the same rats from Experiment 3 collected within $48 \mathrm{~h}$ after the completion of all behavioral tasks, expression of TLR4 mRNA was significantly elevated within the NAcc of rats treated with morphine as adolescents: ${ }^{*} p<0.05$, compared with all other groups. This effect was prevented by treatment with ibudilast at the time of adolescence.

tially gated based on forward and side scatter (Fig. 8A), then subsequently gated for $\mathrm{CD}_{1} \mathrm{~b}^{+}$expression (microglia) or $\mathrm{CD}_{11 \mathrm{~b}^{-}}{ }^{-}$expression as well as TLR4 ${ }^{+}$expression or TLR4 ${ }^{-}$ex- $^{-}$ pression after flow cytometry (Fig. $8 B$ ). We determined that, on average, $97.9 \pm 0.8 \%$ of CD $11 b^{+}$cells from the NAcc and $93.4 \pm$ $1.52 \%$ of the cells from the HP were $\mathrm{TLR}^{+}{ }^{+}$, whereas only $\sim 2.1 \pm 0.32 \%$ of the $\mathrm{CD}_{11 \mathrm{~b}^{-}}$cells from the NAcc and $8.4 \pm$ $0.71 \%$ of the cells from the HP expressed very low levels of TLR 4 staining, not different from unstained controls. These percentages were consistent between rats treated with either morphine or saline during adolescence.

The median fluorescence intensity (MFI) of TLR4 protein on $\mathrm{CD}_{11 \mathrm{~b}}{ }^{+}$cells, microglia, collected from the NAcc in adulthood was significantly greater in rats treated with morphine during adolescence compared with the CD11b ${ }^{+}$ cells from rats treated with saline during adolescence $\left(t_{(8)}=-1.79, p \leq 0.05\right.$; Fig. $8 C)$. In contrast, there were no group differences in TLR4 protein on CD11 ${ }^{+}$cells collected from the HP, indicating that the group difference in NAcc is brain regionspecific $\left(t_{(8)}=-1.03, p=0.33\right.$; Fig. $\left.8 D\right)$. As expected, we found no significant difference in the MFI of TLR4 protein on $\mathrm{CD}_{11}{ }^{-}$cells collected from the NAcc (Fig. 8C) or the HP (Fig. 8D) between the rats previously exposed to morphine or saline during adolescence. Similar to the CD11b mRNA findings collected in earlier experiments, we also found no significant difference in the CD11b MFI measured from CD11b ${ }^{+}$cells taken from the NAcc of rats treated with either saline $(\mathrm{MFI}=2418 \pm 84.3)$ or morphine $(\mathrm{MFI}=2652 \pm 105.8)$ during adolescence $\left(t_{(8)}=-1.52 ; p=0.17\right.$, data not shown). Together, these data indicate that pre-exposure to morphine during adolescence increases the expression of TLR4 protein, a receptor to which morphine can bind directly, on microglia specifically within the mesolimbic reward pathway in adulthood.

\section{Adolescent morphine pre-exposure results in exaggerated TLR4 signaling and microglial activation after morphine treatment in adulthood}

Given these data, we hypothesized that adolescent morphine preexposure would result in exaggerated activation of TLR4 signaling and glial activation within the NAcc in response to morphine treatment in adulthood. To test this, we analyzed the mRNA expression of molecules in the TLR4 signaling pathway and $\mathrm{CD} 11 \mathrm{~b}$ in a group of rats that were pre-exposed to a subchronic regimen of morphine or saline in adolescence (as described in Experiment 1), and treated again as adults with a single dose of morphine or saline $20 \mathrm{~min}$ before being killed. Fourteen genes showed a significant overall effect of adult morphine treatment, including many genes previously determined to be activated by morphine (Table 2) (Schwarz et al., 2011; Hutchinson et al., 2012). Specifically, acute adult morphine treatment increased the mRNA expression of the immediate early gene Jun, mitogenactivated protein kinase 8 [Mapk8 (or the c-Jun N-terminal kinase, JNK1)], the Mapk8 interacting protein 3 (Mapk8ip3), and signaling molecules of the nuclear factor $\kappa \mathrm{B}(\mathrm{NF} \kappa \mathrm{b} 1)$ complex, including $\mathrm{NF} \kappa \mathrm{b}, \mathrm{Nf} \kappa \mathrm{bib}$ (NF $\mathrm{b}$ inhibitor $\beta$ ), Nfkbill $(\mathrm{Nf} \kappa \mathrm{b}$ inhibitor-like protein 1), Tbk1 (TANK binding kinase 1), and the astrocyte marker glial fibrillary acidic protein (GFAP). As previously seen, TLR4 mRNA was the only gene that revealed a significant main effect of adolescent treatment (Fig. 9, $F_{(1,31)}=5.09$; $p=0.03)$. Five genes showed a significant interaction between adolescent morphine pre-exposure and adult morphine treatment, including $\operatorname{CD} 14\left(F_{(1,15)}=8.85 ; p<0.01\right), \operatorname{Myd} 88\left(F_{(1,15)}=\right.$ $5.15 ; p<0.01), \operatorname{NF} \kappa \mathrm{b} 2\left(F_{(1,15)}=7.03 ; p=0.01\right), \operatorname{Map} 4 \mathrm{k} 4\left(F_{(1,15)}\right.$ $=7.88 ; p<0.01)$, and CD11b $\left(F_{(1,31)}=3.90 ; p<0.01\right)$. Specifically, post hoc analysis of CD14, Myd88, NFкb2, and CD11b revealed a significant interaction of adolescent and adult treatment, such that only rats treated with morphine as adolescents and again as adults showed significantly elevated levels of the TLR signaling molecules and the microglial activation marker com- 

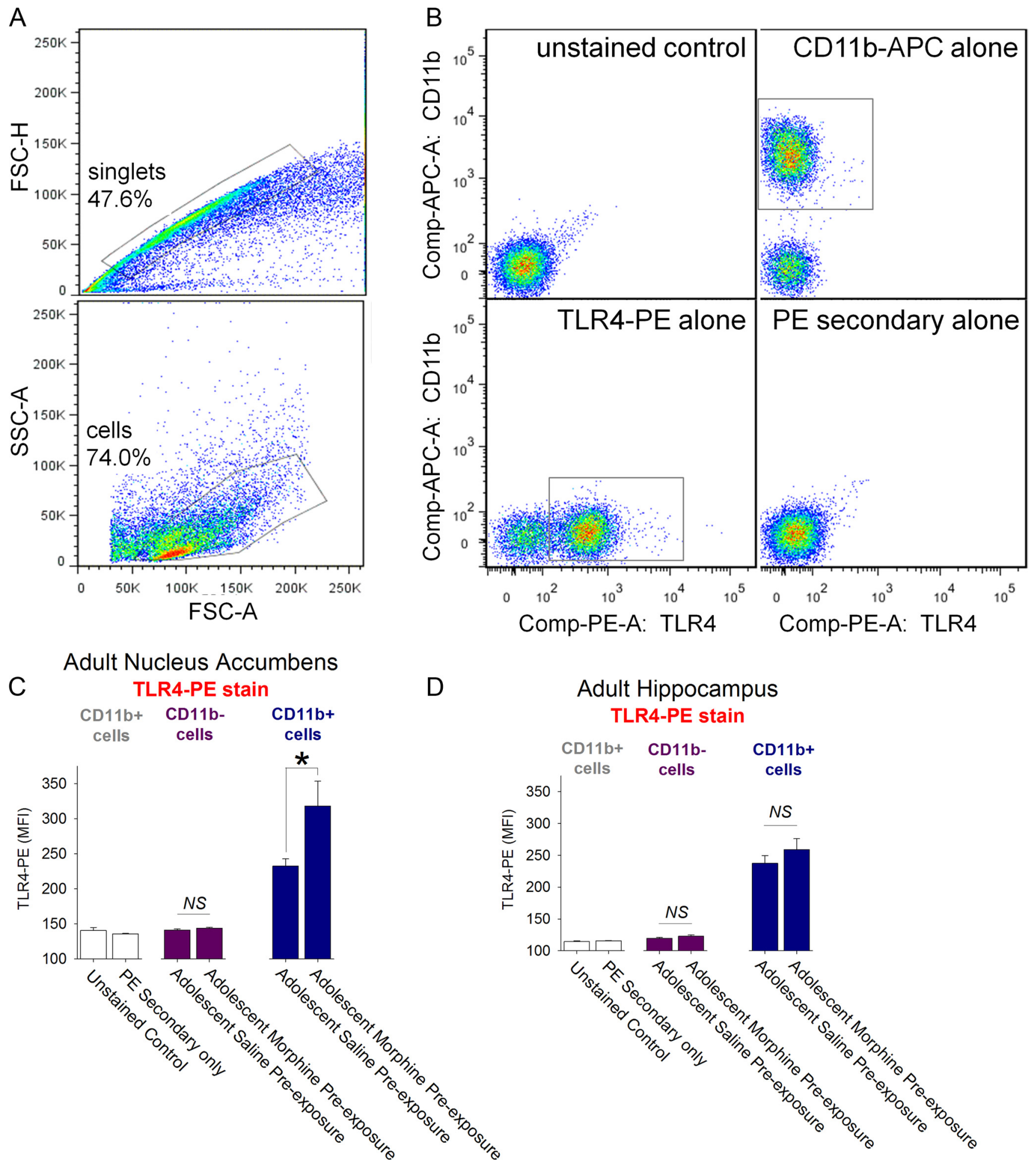

Figure 8. Adolescent morphine exposure results in increased TLR4 protein expression specifically on microglia from the NAcc. $A$, Representative dot plots from dissociated neural tissue of the NAcc represent the gates used to isolate singlets (top) and subsequently cells (bottom). In this particular sample, $46 \%$ of all events were identified as singlets; and from that population, $74 \%$ were living cells. B, Dot plots of staining controls (unstained control, CD11b-allophycocyanin alone, TLR4-phycoerythrin alone, and phycoerythrin secondary alone) following flow cytometry and analysis. Boxes represent gates for CD11b ${ }^{+}$cells (top right) and TLR4 ${ }^{+}$cells (bottom left). C, The bar graph represents the MFI of TLR4 staining from distinct cell populations of NAcc tissue collected in adulthood from rats previously exposed to morphine or saline in adolescence. TLR4 staining was significantly elevated in CD11b ${ }^{+}$cells from the NAcc of rats previously exposed to morphine in adolescence $(p \leq 0.05)$ but was not significantly different in CD11b ${ }^{-}$cells $(n=5 /$ group). $D$, TLR4 staining was not significantly affected by adolescent morphine treatment in hippocampus of either $\mathrm{CD}_{11 b^{+}}$or $\mathrm{CD}_{11 \mathrm{~b}}{ }^{-}$cells from the same rats ( $n=5 /$ group). 
Table 2. Genes exhibiting a significant overall effect of morphine treatment in adulthood

\begin{tabular}{|c|c|c|c|c|c|c|}
\hline Gene & Accession no. & $\begin{array}{l}\text { Adolescent saline and } \\
\text { adult saline treatment }\end{array}$ & $\begin{array}{l}\text { Adolescent saline and } \\
\text { adult morphine treatment }\end{array}$ & $\begin{array}{l}\text { Adolescent morphine and } \\
\text { adult saline treatment }\end{array}$ & $\begin{array}{l}\text { Adolescent morphine and } \\
\text { adult saline treatment }\end{array}$ & $p$ \\
\hline Casp8 & NM_022277 & $2.30 \pm 0.59$ & $3.41 \pm 0.51$ & $2.31 \pm 0.45$ & $5.10 \pm 0.97$ & 0.01 \\
\hline GFAP & NM_017009.2 & $1.44 \pm 0.12$ & $1.85 \pm 0.30$ & $1.52 \pm 0.09$ & $2.06 \pm 0.19$ & 0.01 \\
\hline Jun & NM_021835 & $1.20 \pm 0.1$ & $1.66 \pm 0.15$ & $1.3 \pm 0.08$ & $1.98 \pm 0.22$ & 0.002 \\
\hline Mal & NM_012798 & $2.53 \pm 0.22$ & $1.03 \pm 0.01$ & $2.7 \pm 0.24$ & $0.89 \pm 0.29$ & 0.001 \\
\hline Mapk8 & XM_341399 & $1.14 \pm 0.05$ & $2.14 \pm 0.18$ & $1.2 \pm 0.04$ & $2.03 \pm 0.29$ & 0.001 \\
\hline Mapk8ip3 & NM_001100673 & $1.08 \pm 0.04$ & $1.49 \pm 0.07$ & $1.18 \pm 0.06$ & $1.7 \pm 0.21$ & 0.002 \\
\hline Nfkb1 & XM_342346 & $1.10 \pm 0.09$ & $1.36 \pm 0.03$ & $1.13 \pm 0.10$ & $1.59 \pm 0.17$ & 0.006 \\
\hline Nfkbib & NM_030867 & $1.88 \pm 0.42$ & $4.75 \pm 0.71$ & $2.2 \pm 0.39$ & $4.64 \pm 0.52$ & 0.001 \\
\hline Nfkbil1 & NM_212509 & $1.46 \pm 0.13$ & $1.9 \pm 0.10$ & $1.37 \pm 0.15$ & $2.46 \pm 0.30$ & 0.001 \\
\hline $\mathrm{Nr} 2 \mathrm{C} 2$ & NM_017323 & $1.53 \pm 0.03$ & $2.29 \pm 0.06$ & $1.56 \pm 0.05$ & $1.81 \pm 0.28$ & 0.005 \\
\hline Ptgs2 & NM_017232 & $1.29 \pm 0.15$ & $2.98 \pm 0.25$ & $1.27 \pm 0.15$ & $4.26 \pm 1.24$ & 0.003 \\
\hline Sarm1 & NM_001105817 & $1.11 \pm 0.08$ & $1.51 \pm 0.01$ & $1.22 \pm 0.10$ & $1.91 \pm 0.23$ & 0.001 \\
\hline Tbk1 & NM_001106786 & $1.20 \pm 0.09$ & $1.54 \pm 0.07$ & $1.25 \pm 0.13$ & $1.72 \pm 0.17$ & 0.006 \\
\hline Tollip & NM_001109668 & $1.31 \pm 0.07$ & $1.75 \pm 0.20$ & $1.31 \pm 0.13$ & $1.83 \pm 0.23$ & 0.01 \\
\hline
\end{tabular}

Adolescent rats were pre-exposed to a subchronic regimen of morphine or saline and then treated with a single dose of either morphine ( $4 \mathrm{mg} / \mathrm{kg}$ ) or saline in adulthood. This table shows the genes that exhibited a significant overall effect of adult morphine treatment (two-way ANOVA).

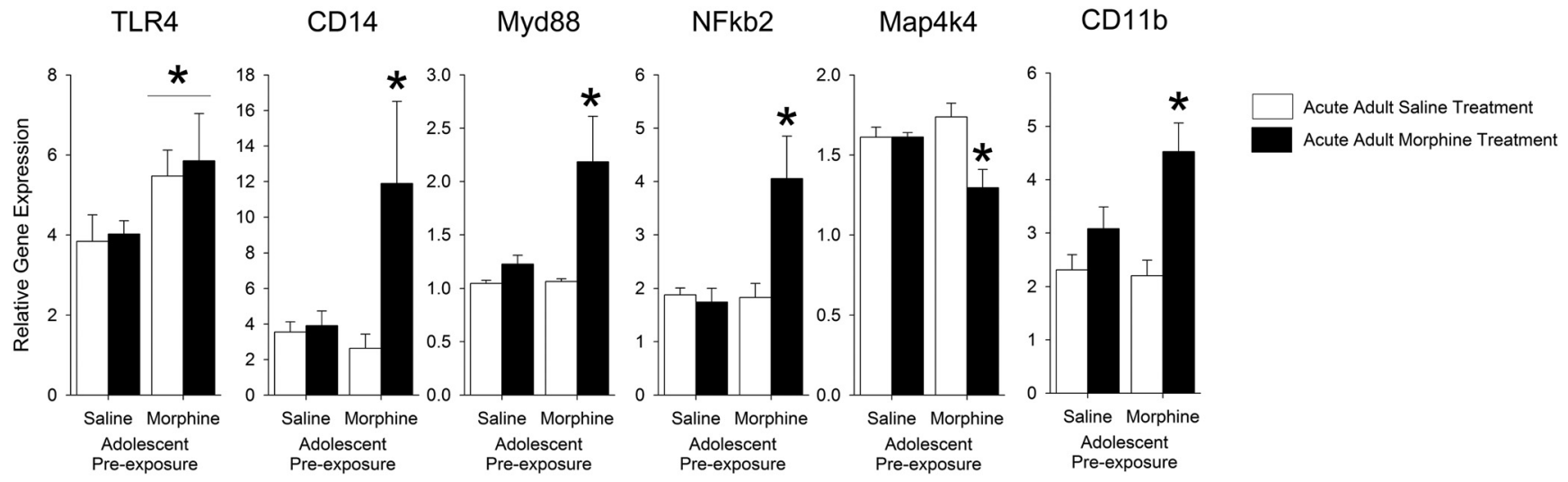

Figure 9. Adolescent morphine pre-exposure increases the activation of the TLR4 signaling pathway and microglia within the NAcc after re-exposure to morphine in adulthood. Adolescent rats were pre-exposed to a subchronic regimen of morphine or saline and then treated with a single dose of either morphine $(4 \mathrm{mg} / \mathrm{kg})$ or saline in adulthood. Analysis of TLR4 mRNA within the NAcc revealed a significant main effect of adolescent morphine treatment: ${ }^{*} p<0.05$, compared with adolescent saline treatment. Analysis of $C D 14$, Myd88, NF $\kappa$ b2, and CD11b revealed a significant interaction of adolescent morphine treatment and adult morphine treatment, such that only rats treated with morphine at both time points showed significantly elevated levels of each gene within NAcc: ${ }^{*} p<0.05$, compared with all other treatment groups. In contrast, analysis of Map4k4 mRNA revealed a significant decrease in rats treated with morphine at both time points compared with all other treatment groups.

pared with all other treatment groups (Fig. 9, $p<0.05$ ). Analysis of Map4k4 revealed the exact opposite pattern (Fig. 9, $p<0.05$ ).

\section{Discussion}

We demonstrate that rats exposed to morphine during adolescence exhibit an increased risk of reinstatement to drug-seeking behavior in adulthood, and treatment of rats with morphine during adolescence causes a long-lasting increase in the expression of TLR4 on microglia specifically within the NAcc. TLR4 is an innate immune receptor to which morphine can bind directly (Hutchinson et al., 2012). Although the activation of TLR4 by bacteria results in a robust increase in the synthesis of many cytokines and chemokines, morphine induces the activation of microglia, resulting in a robust increase in the synthesis of a select group of cytokines and chemokines within the NAcc, including interferon- $\gamma$, CCL25, CCL12, CCL21b, CCL4, and CCL17 (Schwarz et al., 2011). Although the specific function of these cytokines and chemokines within the NAcc is currently unknown, we know that their expression specifically within the NAcc at the time of morphine conditioning is necessary for the drug-induced reinstatement of morphine CPP months later. Specifically, the drug-induced reinstatement of morphine CPP can be blocked by preventing their expression directly within the NAcc via ibudilast infusion at the time of morphine CPP (Schwarz et al., 2011). Consistent with these findings, we present three novel pieces of data related to the risk of drug-induced reinstatement: (1) rats treated with morphine during adolescence exhibit increased levels of TLR4 specifically on microglia within the NAcc and exhibit exaggerated TLR4 signaling and microglial activation within the NAcc after morphine re-exposure in adulthood; (2) rats treated with morphine during adolescence exhibit an increased risk of drug-induced reinstatement of morphine CPP in adulthood; and (3) blocking the activation of glia with ibudilast during morphine treatment in adolescence prevents the long-term increase in TLR4 expression within the NAcc and prevents the increased risk of drug-induced reinstatement of morphine CPP in adulthood.

Using flow cytometry of rapidly isolated neural tissue, we determined that TLR4 is selectively expressed on microglia from both the NAcc and the hippocampus. Others report that TLR4 is also present on astrocytes; however, we found virtually no protein expression of TLR4 on other cell types rapidly isolated from these two brain regions. The reports indicating TLR4 expression on astrocytes and sometimes neurons use either models of disease 
or stroke (Saito et al., 2010; Casula et al., 2011; Yoo et al., 2011; Zurolo et al., 2011), collect tissue from the spinal cord (Saito et al., 2010), or measure expression in cultured astrocytes (Gorina et al., 2011; Santos-Galindo et al., 2011), suggesting that TLR4 expression may be specific to microglia, except perhaps in pathological or artificial conditions. In our model, we hypothesize that adolescent morphine pre-exposure increases TLR4 expression on microglia within the NAcc, which results in exaggerated activation of the TLR4 signaling pathway (Fig. 9) and exaggerated activation of microglia (Fig. 9) after morphine treatment in adulthood. Although these collective data are supportive of our working hypothesis, the causal experiments that would link elevated TLR4 expression specifically within the NAcc to elevated reinstatement to drug-seeking behavior remain to be performed.

These long-term changes in microglial function were induced specifically by morphine exposure in adolescence. Rats exposed to morphine in adulthood did not exhibit a constitutive increase in TLR4 expression within the NAcc and did not exhibit an increased risk of drug-induced reinstatement of morphine CPP. Approximately half of the rats pre-exposed to morphine as adults showed reinstatement of morphine CPP after morphine reexposure, whereas the other half did not (similar to controls); the majority of rats treated with morphine during adolescence showed reinstatement of morphine CPP after morphine reexposure. Using the same CPP-reinstatement paradigm, we find that, when rats have not had a pre-exposure condition (i.e., the rats were not handled significantly or injected before initiating CPP in adulthood), the majority of rats show robust reinstatement of morphine CPP after drug re-exposure (Schwarz et al., 2011), suggesting that the handling or injections involved in preexposure, either during adolescence or in adulthood, decrease the risk of drug-induced reinstatement to morphine CPP. Importantly, this effect is overshadowed by the significant increase in the risk of reinstatement caused by pre-exposure to morphine during adolescence, replicated in Figures 2 and 5. We hypothesize that this paradigm more accurately represents the human population in which not all individuals exposed to drugs of abuse become addicted, and this paradigm has allowed us to identify a specific factor (e.g., adolescent exposure to drugs of abuse) that increases an individual's risk of addiction and relapse and the neural mechanisms underlying this increased risk. Together, we suggest that the adolescent period may be a particularly sensitive period for changes in TLR4 signaling and microglial function caused by adolescent morphine use that ultimately results in an increased risk of reinstatement to drug-seeking behavior.

Pretreatment with ibudilast during adolescence prevents the constitutive increase in TLR4 expression within the NAcc and decreases the risk of drug-induced reinstatement to drug-seeking behavior in adulthood. Although ibudilast inhibits the function of both microglia and astrocytes, we hypothesize that ibudilastinduced inhibition of microglia in particular prevents these longterm changes in the brain and behavior. First, we hypothesize that morphine activates TLR4 on microglia, initiating an inflammatory response that involves a cascade of cytokine and chemokine expression potentially derived from both microglia and astrocytes (and even neurons), which in turn modulates neural function and reinstatement behavior. Second, we have previously shown that events that occur during development can significantly influence the developmental trajectory of microglia within the brain (Schwarz and Bilbo, 2011; Williamson et al., 2011). Microglia are a long-lived cell population that may reside in the brain for the life of the animal (Bland et al., 2010b). A single early-life insult may have an enduring influence on their pheno- type (Bland et al., 2010a; Williamson et al., 2011). We determined that adolescent morphine treatment caused a long-term constitutive increase in TLR4 expression on microglia, which may be the result of epigenetic modifications to the TLR4 gene; however, the mechanisms underlying this constitutive increase in TLR4 expression and the mechanism by which ibudilast inhibits this long-term change in the brain remain to be determined. We can conclude that microglia within the adolescent brain, particularly within the NAcc, are more plastic or mutable relative to microglia within the adult brain, such that activation of glia, either microglia or astrocytes, in adolescence can influence cell function acutely and subsequently have a long-term impact on TLR4 signaling and microglia function into adulthood.

Minocycline administered at the dose used in Experiment 1 attenuates morphine-induced microglial activation, reward, and respiratory depression and enhances morphine analgesia (Hutchinson et al., 2008). Thus, we were initially surprised to find that attenuating microglial activation with minocycline at the time of drug-induced reinstatement could not prevent the reinstatement of drug-seeking behavior in rats treated with morphine as adolescents. However, the lack of effect of minocycline on immediate preference in the reinstatement experiment is entirely consistent with our previous finding that inhibiting glia with ibudilast at the time of initial morphine experience does not impact CPP but does block subsequent reinstatement (Schwarz et al., 2011). Taken in the context of these previous findings, our data suggest that minocycline has no effect on the associative properties of morphine after they are already established. In contrast, preventing microglial activation at the time of conditioning can significantly prevent the risk of reinstatement after morphine re-exposure weeks later. Thus, although we predict that morphine re-exposure reactivates microglia at the time of reinstatement, and in the case of rats exposed during adolescence this activation is exaggerated, we think that this microglial activation has no effect on immediate preference assessed at the time of morphine reinstatement. Rather, we predict it would inhibit future episodes of morphine-induced reinstatement behavior.

Analysis of TLR4 signaling and microglial activation within the NAcc after morphine treatment of adult rats previously exposed to morphine in adolescence revealed an interesting pattern. Many genes exhibited a selective increase in expression after adult morphine treatment that was amplified by previous adolescent morphine exposure. Although we do know that morphine-induced activation of microglia and production of proinflammatory cytokines and chemokines increase the risk of drug-induced reinstatement of drug-seeking behavior months later (Schwarz et al., 2011), the exact mechanisms by which microglia and their specific immune products lead to these long-term changes in the neural circuitry underlying drug-induced reinstatement of CPP are currently unknown. Further research examining neuronal-glial interactions and the influence of specific cytokines and chemokines at the time of morphine conditioning may yield novel insight into the neural mechanisms underlying drug-seeking behavior after subsequent re-exposures to morphine.

In conclusion, these data present a novel perspective on the role of the neuroimmune system in the long-term risk of addiction. Specifically, these data indicate that adolescence may represent a particularly sensitive period for morphine-induced alterations in the TLR4 signaling pathway and the function of microglial cells within the NAcc. This shift in microglial function can, in turn, increase the risk of negative consequences after drug treatment later in life, such that these individuals may harbor 
long-term changes in the neural circuitry that promote the cycle of morphine addiction and relapse.

\section{References}

Baumrind D (1987) A developmental perspective on adolescent risk taking in contemporary America. New Dir Child Dev 37:93-125. Medline

Bilbo SD (2010) Early-life infection is a vulnerability factor for aging-related glial alterations and cognitive decline. Neurobiol Learn Mem 94:57-64. CrossRef Medline

Bilbo SD, Tsang V (2010) Enduring consequences of maternal obesity for brain inflammation and behavior of offspring. FASEB J 24:2104-2115. CrossRef Medline

Bland ST, Beckley JT, Watkins LR, Maier SF, Bilbo SD (2010a) Neonatal Escherichia coli infection alters glial, cytokine, and neuronal gene expression in response to acute amphetamine in adolescent rats. Neurosci Lett 474:52-57. CrossRef Medline

Bland ST, Beckley JT, Young S, Tsang V, Watkins LR, Maier SF, Bilbo SD (2010b) Enduring consequences of early-life infection on glial and neural cell genesis within cognitive regions of the brain. Brain Behav Immun 24:329-338. CrossRef Medline

Casula M, Iyer AM, Spliet WG, Anink JJ, Steentjes K, Sta M, Troost D, Aronica E (2011) Toll-like receptor signaling in amyotrophic lateral sclerosis spinal cord tissue. Neuroscience 179:233-243. CrossRef Medline

Cunningham CL, Gremel CM, Groblewski PA (2006) Drug-induced conditioned place preference and aversion in mice. Nat Protoc 1:1662-1670. CrossRef Medline

Galvan A, Hare TA, Parra CE, Penn J, Voss H, Glover G, Casey BJ (2006) Earlier development of the accumbens relative to orbitofrontal cortex might underlie risk-taking behavior in adolescents. J Neurosci 26: 6885-6892. CrossRef Medline

Gorina R, Font-Nieves M, Márquez-Kisinousky L, Santalucia T, Planas AM (2011) Astrocyte TLR4 activation induces a proinflammatory environment through the interplay between MyD88-dependent NFkappaB signaling, MAPK, and Jak1/Stat1 pathways. Glia 59:242-255. CrossRef Medline

Hutchinson MR, Northcutt AL, Chao LW, Kearney JJ, Zhang Y, Berkelhammer DL, Loram LC, Rozeske RR, Bland ST, Maier SF, Gleeson TT, Watkins LR (2008) Minocycline suppresses morphine-induced respiratory depression, suppresses morphine-induced reward, and enhances systemic morphine-induced analgesia. Brain Behav Immun 22:1248-1256. CrossRef Medline

Hutchinson MR, Zhang Y, Shridhar M, Evans JH, Buchanan MM, Zhao TX, Slivka PF, Coats BD, Rezvani N, Wieseler J, Hughes TS, Landgraf KE, Chan S, Fong S, Phipps S, Falke JJ, Leinwand LA, Maier SF, Yin H, Rice KC, Watkins LR (2010) Evidence that opioids may have Toll-like receptor 4 and MD-2 effects. Brain Behav Immun 24:83-95. CrossRef Medline

Hutchinson MR, Northcutt AL, Hiranita T, Wang X, Lewis SS, Thomas J, van Steeg K, Kopajtic TA, Loram LC, Sfregola C, Galer E, Miles NE, Bland ST, Amat J, Rozeske RR, Maslanik T, Chapman TR, Strand KA, Fleshner M, Bachtell RK, Somogyi AA, Yin H, Katz JL, Rice KC, Maier SF, Watkins LR.
(2012) Opioid activation of Toll-like receptor 4 contributes to drug reinforcement. J Neurosci 32:11187-11200. CrossRef Medline

Imai Y, Ibata I, Ito D, Ohsawa K, Kohsaka S (1996) A novel gene ibal in the major histocompatibility complex class III region encoding an EF hand protein expressed in a monocytic lineage. Biochem Biophys Res Commun 224:855-862. CrossRef Medline

Paxinos G, Watson C (2005) The rat brain in stereotaxic coordinates, Ed 5. New York: Academic.

Robins LN, Przybeck TR (1985) Age of onset of drug use as a factor in drug and other disorders. NIDA Res Monogr 56:178-192. Medline

Saito O, Svensson CI, Buczynski MW, Wegner K, Hua XY, Codeluppi S, Schaloske RH, Deems RA, Dennis EA, Yaksh TL (2010) Spinal glial TLR4-mediated nociception and production of prostaglandin E(2) and TNF. Br J Pharmacol 160:1754-1764. CrossRef Medline

Santos-Galindo M, Acaz-Fonseca E, Bellini MJ, Garcia-Segura LM (2011) Sex differences in the inflammatory response of primary astrocytes to lipopolysaccharide. Biol Sex Differ 2:7. CrossRef Medline

Schwarz JM, Bilbo SD (2011) LPS elicits a much larger and broader inflammatory response than Escherichia coli infection within the hippocampus of neonatal rats. Neurosci Lett 497:110-115. CrossRef Medline

Schwarz JM, Hutchinson MR, Bilbo SD (2011) Early-life experience decreases drug-induced reinstatement of morphine CPP in adulthood via microglial-specific epigenetic programming of anti-inflammatory IL-10 expression. J Neurosci 31:17835-17847. CrossRef Medline

Simoni-Wastila L, Yang HK (2006) Psychoactive drug abuse in older adults. Am J Geriatr Pharmacother 4:380-394. CrossRef Medline

Spear LP (2000) The adolescent brain and age-related behavioral manifestations. Neurosci Biobehav Rev 24:417-463. CrossRef Medline

Wang X, Loram LC, Ramos K, de Jesus AJ, Thomas J, Cheng K, Reddy A, Somogyi AA, Hutchinson MR, Watkins LR, Yin H (2012) Morphine activates neuroinflammation in a manner parallel to endotoxin. Proc Natl Acad Sci U S A 109:6325-6330. CrossRef Medline

Williamson LL, Sholar PW, Mistry RM, Smith SH, Bilbo SD (2011) Microglia and memory: modulation by early-life infection. J Neurosci 31:15511-15521. CrossRef Medline

Wills TA, Vaccaro D, McNamara G (1994) Novelty seeking, risk taking, and related constructs as predictors of adolescent substance use: an application of Cloninger's theory. J Subst Abuse 6:1-20. CrossRef Medline

Wills TA, Vaccaro D, McNamara G, Hirky AE (1996) Escalated substance use: a longitudinal grouping analysis from early to middle adolescence. J Abnorm Psychol 105:166-180. CrossRef Medline

Yoo KY, Yoo DY, Hwang IK, Park JH, Lee CH, Choi JH, Kwon SH, Her S, Lee YL, Won MH (2011) Time-course alterations of Toll-like receptor 4 and NF-kappaB p65, and their coexpression in the gerbil hippocampal CA1 region after transient cerebral ischemia. Neurochem Res 36:2417-2426. CrossRef Medline

Zurolo E, Iyer A, Maroso M, Carbonell C, Anink JJ, Ravizza T, Fluiter K, Spliet WG, van Rijen PC, Vezzani A, Aronica E (2011) Activation of Toll-like receptor, RAGE and HMGB1 signalling in malformations of cortical development. Brain 134:1015-1032. CrossRef Medline 